\title{
A COMPARATIVE STUDY TO KNOW THE INCIDENCE OF POST-DURAL PUNCTURE HEADACHE FOLLOWING SUBARACHNOID BLOCK USING 27 G QUINCKE'S AND WHITACRE NEEDLES - A RANDOMIZED CLINICAL TRIAL
}

\author{
Shivanand Laxman Karigar1, Basvaraj Patil ${ }^{2}$
}

${ }_{1}^{1}$ Assistant Professor, Department of Anaesthesia, BLDEU, Shri B. M. Patil Medical College, Vijaypur. ${ }_{2}^{2}$ Assistant Professor, Department of Anaesthesia, BLDEU, Shri B. M. Patil Medical College, Vijaypur.

ABSTRACT
BACKGROUND
The introduction of local anaesthetic solutions into subarachnoid space produces Spinal Anaesthesia (SA). Spinal anaesthesia can
be used either alternative to the general anaesthesia or can be used simultaneously with general anaesthesia or afterwards for post-
operative analgesia and for the management of acute and chronic pain disorder.

\section{OBJECTIVES}

The study is carried out to evaluate the following parameters on using 27G Quincke's and Whitacre's spinal needles and to know the incidence of post dural puncture headache.

\section{METHODOLOGY}

The present study was conducted in the Department of Anaesthesiology, BLDEU, Shri B.M. Patil Medical College, Vijaypur, from January 2015 to December 2015. Patients between the age of 20 to 60 years with ASA grade I and II undergoing lower abdominal and lower limb surgeries were included.

\section{RESULTS}

Females outnumbered males in both the groups (56.1\% and 57.2\%) with male-to-female ratio of 1:1.31 in Quincke group and 1:1.37 in Whitacre group. Majority (30.13\%) of the patients had age between 20 to 29 years in Quincke group compared to $30.12 \%$ of the patients in the age ranging from 50 to 60 years in Whitacre group. The incidence of PDPH is 3.1\% in Quincke group and 1.1\% patients in Whitracre group and this difference was statistically significant $(\mathrm{p}<0.005)$.

\section{CONCLUSION}

Overall, the Whitacre $27 \mathrm{G}$ needle has better results with respect to PDPH.

\section{KEYWORDS}

Post Dural Puncture Headache; Sub-Arachnoid Block; Quincke Needle; Whitacre Needle.

HOW TO CITE THIS ARTICLE: Karigar SL, Patil B. A comparative study to know the incidence of post-dural puncture headache following subarachnoid block using 27 G Quincke's and Whitacre needles - a randomized clinical trial. J. Evolution Med. Dent. Sci. 2016;5(49):3136-3139, DOI: 10.14260/jemds/2016/728

\section{INTRODUCTION}

The use of regional anaesthesia, especially spinal anaesthesia has been part of anaesthesia practice for decades. Despite advances in equipment and spinal anaesthesia technique postdural puncture headache remains a persistent problem. Postdural puncture headache can be best explained by prolonged cerebrospinal fluid leakage occurring from the site of dural puncture created by the spinal needle during administration of spinal anaesthesia. Prolonged leakage of CSF leads increase in bouncy of brain weight, so it will have pressure on cranial nerves which in turn causes headache. Usually, it starts after 48 hours of anaesthesia, characteristically it increases on standing and relieved by lying down position. Delayed closure of the dural defect, which may take up to a week or more will also contribute. ${ }^{1}$

Financial or Other, Competing Interest: None.

Submission 24-05-2016, Peer Review 01-06-2016,

Acceptance 03-06-2016, Published 18-06-2016.

Corresponding Author:

Dr. Shivanand Laxman Karigar,

Assistant Professor,

Department of Anaesthesia,

BLDEU, Shri B.M. Patil Medical College,

Vijaypur.

E-mail: shivanandkarigar82@gmail.com

DOI: $10.14260 /$ jemds $/ 2016 / 728$
August Bier first used it deliberately on $16^{\text {th }}$ August 1898 with $3 \mathrm{~mL}$ of $0.5 \%$ cocaine. On 24th August, he was administered spinal anaesthesia by his assistant. During the attempt, a lot of Cerebrospinal Fluid (CSF) was lost and Bier developed Post Dural Puncture Headache (PDPH) and this was the first documented case of PDPH. ${ }^{2}$ Since then it has passed through phases, characterized by overly enthusiastic acceptance followed by phases of rejection. Spinal anaesthesia has become popular because it results in good sympathetic blockade, sensory analgesia, profound muscle relaxation and less operative blood loss. However, the fear of precipitating PDPH after spinal anaesthesia currently limits the use since the incidence of this complication is directly related to gauges (G) and types of needle. Various gauges and tips have been devised to reduce the incidence of PDPH. The newly introduced Whitacre needle is associated with lesser incidence of PDPH. ${ }^{3}$

Because dural puncture is a principal factor contributing to post dural puncture headache, many anaesthesiologists believe that spinal needle size should be 25 -gauge or smaller. This study is intended to assess the various factors influencing the occurrence of post dural puncture headache. Identification of risk factors of the post dural puncture headache and evaluation is a crucial step in rational modification of anaesthetic technique which will allow timely recognition, 
appropriate therapeutic interventions and prevent post-dural puncture headache.

\section{History of Spinal Anaesthesia. ${ }^{1}$}

Spinal anaesthesia consists of temporary interruption of nerve transmission within the subarachnoid space produced by injection of a local anaesthetic solution into CSF. Used widely, solely and successfully for almost 100 years, spinal anaesthesia has many potential advantages over general anaesthesia, especially involving the lower abdomen, perineum and lower extremities.

Spinal anaesthesia was initially produced inadvertently by J. Leonard Corning, a neurologist in New York in 1885. He accidentally pierced the dura mater, while experimenting with cocaine on spinal nerves of a dog. But spinal anaesthesia could not become an acceptable means for use of cocaine until a safe predictable means for performing lumbar puncture was described. Quincke did this in 1891. In 1899, August Bier used Quincke's technique to inject cocaine in order to produce operative anaesthesia in 6 patients, the first real spinal anaesthesia. In the same year, Matas in New Orleans and Tuffier in France also reported on the use of cocaine spinal anaesthesia. However, the popularity of cocaine SA was limited owing to the high incidence of CNS side effects like tremors, hyperreflexia, severe headache and muscle spasm and pains.

Procaine was the first synthetic local anaesthetic to be used. Einhorn prepared it in 1904. In 1905, Heinrich Brown, German surgeon, reported the use of procaine for operative SA. The understanding of causes of spinal anaesthesia induced hypotension and its management was described by clinicians like Babcock, Koster, Labat and Pitker.

Alfred E. Barker, was the first to realize in 1906, the importance of curves of vertebral column and use of hyperbaric procaine solutions by adding glucose. Sise used later tetracaine in 1935. Dibucaine was synthesized and used by Jones in 1930. Lemmom in 1940 and Tuohy in 1945 described continuous spinal anaesthesia. Bupivacaine was first introduced in 1966.

Between 1945 and 1965, SA was neglected mainly due to fear of neurologic complications. In recent years, there has been a steady increase in the popularity of SA for surgeries. In India, bupivacaine is now the anaesthetic readily available for subarachnoid injection and it is used as a $0.5 \%$ solution, heavy (Hyperbaric).

\section{Path Physiology of PDPH}

Post-Dural Puncture Headache (PDPH) is a common sequelae to LP. Bier, The German surgeon who first demonstrated spinal anaesthesia, was also the first to propose that PDPH was caused by leakage of CSF through the hole created in the dura mater.

PDPH is a constellation of symptoms seen in patients who have received Intentional or unintentional penetration of the dura mater, either during epidural or spinal placement or during therapeutic or diagnostic LP. PDPH is defined as bilateral headache that is related with position, especially improvement during recumbent and worsening during upright position of the body. The pain may be throbbing in nature and is extremely variable in severity. The International Headache Society classified it as one that occurs or worsens less than 15 minutes after assuming the upright position and disappears or improves less than 30 minutes after resuming the recumbent position.

The headache is typically transient, develops within 2-5 days and spontaneously resolves within $2 \mathrm{wks}$. PDPH typically occurs within $48 \mathrm{hrs}$. The drainage of $20 \mathrm{~mL}$ of CSF consistently produces headache. In many cases, the headache is mild in intensity and brief in duration without significant sequelae. PDPH is occasionally severe enough to leave patients bedridden and it often delays hospital discharge, PDPH can be prolonged with reports of symptoms lasting months or even years; untreated PDPH can lead to the development of persistent cranial nerve palsies and even subdural haematoma.

Early phase headache ( $<36$ hours) due to residual anaesthetic could cause intracranial vasoconstriction and second suggestion was that the effect is caused by the large concentration of glucose acting as an osmotic agent or an irritant Dual mechanism are there for the PDPH syndrome. Firstly, this headache is related with ongoing leakage of Cerebrospinal Fluid through the dural rent made by the LP needle that exceeds the rate of CSF production. The loss of the cushioning effect of CSF allows the brain to sag within the skull. The sagging brain in the upright patient places traction on intracranial vessel. These intracranial vessels transmit pain. The stimulus is refereed along the frontal division of the trigeminal nerves as well as the ninth and tenth cranial nerves to the occiput and via the upper cervical nerves to the neck and shoulders. Secondly reflex vasodilatation caused by traction on these veins results in a throbbing quality to the pain. Dural puncture or a rent in the dura with prolonged CSF leakage may cause non-infectious arachnoiditis and may be associated with urinary and fecal incontinence.

\section{Factors Affecting Post-Dural Puncture Headache}

1. Age and Sex of the patient.

2. Experience of the physician performing the procedure.

3. Single or multiple puncture.

4. Time to mobilization.

5. Hydration status of the patient in the perioperative period.

6. Size of the needle and bevel of the needle.

7. BMI and previous history of headache.

Higher incidence with the larger needle. Smaller needle size is associated with lesser risk of headache according to a smaller tear in the dura and less potential for leakage.

The incidence is greater in patients with a small Body Mass Index (BMI). Patients with headache before or during the LP or a history of prior PDPH are at greater risk for PDPH including prevalence and severity. Incidence of PDPH decreases about $50 \%$. If the bevel of the Quincke is inserted parallel to the dural fibres rather than perpendicular PDPH is considered in the differential diagnosis of Cephalalgia, Migraine, Tumour, Infection, Eclampsia, Subdural haematoma, SA haemorrhage, Benign intracranial HTN, Malignant HTN, Meningitis, Caffeine withdrawal, Pneumocephalus, IC vein thrombosis, Migraine.

The treatment of PDPH should be based on minimizing the leak of CSF, increasing CSF production or translocating CSF from the spinal to the intracranial compartment and also PDPH will be relieved by restoration of intracranial CSF volume, but also that cerebral vasoconstrictor might provide 
symptomatic relief. The treatment of PDPH is traditionally divided into conservative and aggressive treatment.

\section{Conservative Treatment}

Bed rest, Hydration, Prone position, Abdominal binder, Caffeine, Oral or parenteral, Theophylline, Sumatriptan, ACTH/corticosteroids, Aggressive treatment: - Intrathecal catheter, Epidural saline, Epidural blood patch, Prophylactic epidural blood patch, epidural dextran. The mode of treatment depended on severity. Severity of PDPH was defined by duration of PDPH or severe disability grading or VAS.

Disability grading were (1)

- 0 : No disability (If no headache occurred),

- 1: Mild disability (If mild headache, minimally involved activity, not required daytime bed rest),

- 2: Moderate disability (If moderate headache, moderately involved activity required partial daytime bed rest),

- 3: Severe disability (If severe headache, mostly involved activity required all of daytime bed rest and vomiting).

Patients estimated the Visual Analog Scale (VAS) that ranged between 0 through 10 (0: if no pain and 10 if the most severe pain in their life).

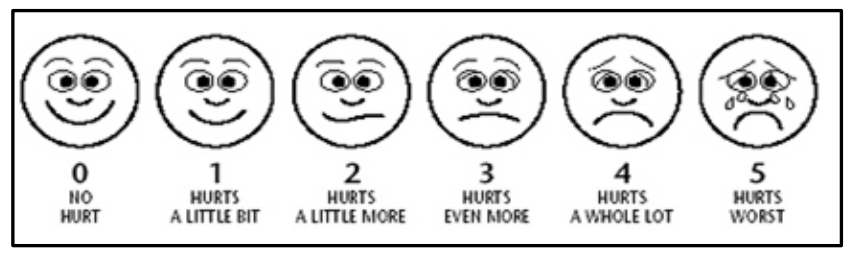

\section{MATERIALS AND METHODS}

The present study was conducted in the Department of Anaesthesiology, BLDEU, Shri B.M. Patil Medical College, Vijaypur, from January 2015 to December 2015. Patients between the age of 20 to 60 years with ASA grade I and II undergoing lower abdominal and lower limb surgeries were included.

98 patients are selected in each group based on the following calculation.

Sample Size $=\frac{2 \mathrm{X}(\mathrm{Z} \alpha+\mathrm{Z} \beta)^{2} \mathrm{XpXq}}{\mathrm{d}^{2}}$

\section{Randomization Procedure}

Based on the above calculation, a total of 196 patients are allocated randomly into group A and group B by using a computer generated randomization table.

\section{Inclusion Criteria}

- Patients undergoing lower abdominal surgeries.

- Patients undergoing lower limb surgeries.

- Age between 20 to 60 years.

- No clinically significant cardiovascular, respiratory and central nervous system disease (ASA Grade I and II).

\section{Exclusion Criteria}

- Patient refusal

- Allergy to Bupivacaine.

- History of bleeding diathesis.

- Severe-to-moderate hypotension.

- Arrhythmias.
- Infection at the site of spinal needle insertion.

- Severe spinal abnormalities like spina bifida, meningocele.

- $\quad$ Raised intracranial tension, hydrocephalus.

\section{PROCEDURE}

The study was approved and ethical clearance was obtained from Human Ethics Committee, BLDEU, Shri B.M. Patil Medical College, Vijaypur. After finding the suitability according to selection criteria, patients were selected for the study and briefed about the nature of the study. The interventions used and written informed consent was obtained. Further, descriptive data of the patients like name, age, sex, detailed history were obtained and recorded on predesigned and pretested proforma.

\section{Anaesthesia Procedure}

Intravenous (IV) line was secured using $18 \mathrm{G}$ cannula. All patients were preloaded with $500 \mathrm{~mL}$ of ringer lactate solution. Electrocardiogram (ECG), Non-Invasive Blood Pressure (NIBP), Oxygen Saturation $\left(\mathrm{SPO}_{2}\right)$ was monitored. Patients of ASA I - II, aged 20 to 60 yrs. undergoing lower abdominal and lower limb surgeries were taken. Patients were allocated into group A and group B by computer generated randomization table. Group A patients received spinal anaesthesia with 27 G Quincke's spinal needle and Group B received spinal anaesthesia with 27 G Whitacre's spinal needle. Under strict aseptic precautions using midline approach 27 G Quincke's or 27 G Whitacre's spinal needle inserted into $\mathrm{L}_{3}-\mathrm{L}_{4}$, subarachnoid space.

A $3 \mathrm{~mL}$ of $0.5 \%$ heavy bupivacaine injected after confirming for free flow of CSF. Experienced anaesthesiologists performed the blocks. Failure of spinal anaesthesia was defined as either inability to elicit free flow of CSF after three attempts or clearly inadequate analgesia for surgery at 15 minutes after giving local anaesthetic. The number of attempts of dural puncture and the presence or absence of tactile identification usually described as a click phenomenon on dural puncture.

Heart Rate (HR), NIBP, $\mathrm{SPO}_{2}$ were recorded every three minutes for 15 minutes, then every five minutes for 30 minutes and thereafter every 10 minutes. All patients were seen on the day of surgery and everyday for 3 days.

\section{Statistical Analysis}

The data was analysed using Microsoft Excel Software. Descriptive statistics was used to analyse the data. Chi-square test was used to find out the association.

RESULT
\begin{tabular}{|c|c|c|}
\hline Indicator & Quincke Group & Whitacre Group \\
\hline \multicolumn{3}{|c|}{ Sex } \\
\hline Male & $43(43.9 \%)$ & $41(42.8 \%)$ \\
\hline Female & $55(56.1 \%)$ & $57(57.2 \%)$ \\
\hline \multicolumn{3}{|c|}{ Age Wise Distribution } \\
\hline 20 to 29 & $30(30.7 \%)$ & $23(23.4 \%)$ \\
\hline 30 to 39 & $23(23.5 \%)$ & $25(25.5 \%)$ \\
\hline 40 to 49 & $23(23.4) \%$ & $20(20.5 \%)$ \\
\hline 50 to 60 & $22(22.4 \%)$ & $30(30.6 \%)$ \\
\hline Total & $\mathbf{9 8}$ & $\mathbf{9 8}$ \\
\hline \multicolumn{2}{|c|}{ Table 1: Distribution of Study Subjects } \\
\hline
\end{tabular}

In this study, females outnumbered males in both the groups $(56.1 \%$ and $57.2 \%)$ with male-to-female ratio of $1: 1.31$ 
in Quincke group and 1:1.37 in Whitacre group. In the present study, majority (30.13\%) of the patients had age between 20 to 29 years in Quincke group compared to $30.12 \%$ of the patients in the age ranging from 50 to 60 years in Whitacre group. The mean age in Whitacre group was $40.74 \pm 12.25$ years, whereas in Quincke group it was $38.58 \pm 11.95$ years.

\begin{tabular}{|c|c|c|}
\hline Indicator & Quincke Group & Whitacre Group \\
\hline Present & $3(3.1 \%)$ & $1(1.1 \%)$ \\
\hline Absent & $95(96.9 \%)$ & $97(98.9 \%)$ \\
\hline Total & $\mathbf{9 8 ( 1 0 0 \% )}$ & $\mathbf{9 8 ( 1 0 0 \% )}$ \\
\hline \multicolumn{3}{|c|}{ Table 2: Incidence of PDPH } \\
\hline
\end{tabular}

$\mathrm{X}^{2}<0.005$, d.f: 1

The above table depicts that $3.1 \%$ patients had PDPH in Quincke group and 1.1\% patients in Whitracre group and this difference was statistically significant $(\mathrm{p}<0.005)$.

\begin{tabular}{|c|c|c|c|}
\hline & Positive & Negative & Total \\
\hline$<4$ hours & $03(3.1 \%)$ & $95(96.9 \%)$ & $98(100 \%)$ \\
\hline$>4$ hours & $01(1.1 \%)$ & $97(98.9 \%)$ & $98(100 \%)$ \\
\hline & 04 & 192 & 196 \\
\hline \multicolumn{3}{|c|}{ Table 3: Effect of Time to Mobilization } \\
in the Study Population \\
\hline
\end{tabular}

In our study, effect of time to mobilization we have observed that only $3.1 \%$ study participants mobilized within 4 hours in positive PDPH participants.

\section{DISCUSSION}

In our study, the female participants constituted 55 (56.1\%) and 57 (57.2\%) in Quincke and Whitacre groups respectively. Contrast to our study findings, Lynch J et al study have shown that 108 were males and 91 were females in Quincke group and 116 were males and 83 were females in Whitacre group. ${ }^{4}$ Despond 0 et al study also has shown male predominance that is 74 males and 23 females in Quincke group and 71 males and 26 females in Whitacre group. ${ }^{5}$ In this study the mean age in Quincke group was $38.58 \pm 11.95$ years, whereas in Whitacre group it was $40.74 \pm 12.25$ years. Lynch J and Despond 0 et al studies reported mean age of $37 \pm 14$ and 32.5 years in Quincke group and $36 \pm 15$ and 31.7 years in Whitacre group respectively.4,5 Lybecker $\mathrm{H}$ et al study in regard to the age, direction of the bevel of the needle and previous history PDPH were found to be significant predicator of PDPH. ${ }^{6}$ Sudlow $\mathrm{C}$ et al did a randomized trial to assess the effects on post-dural puncture headache of a period of bed rest versus early mobilization of different position during a period of bed rest and of administering supplementary fluids after the procedure.

They concluded that there is no evidence to suggest that routine bed rest after dural puncture is beneficial. ${ }^{7}$ Sirakaran Tejavanija et al study has concluded that the prevalence and characteristic of PDPH were not different between the two groups. ${ }^{8}$ Bernard EC et al study have observed that post-dural puncture headache is more frequent using 25 -gauge needle than 26-gauge and occurrence of post-dural puncture headache in patient over the age of 45 years was significantly less frequent than young patient. ${ }^{9}$ Cook PT et al have observed that there is no statistical difference in the development of post-dural puncture headache when recumbency is 4 or 24 hours. ${ }^{10}$

\section{CONCLUSION}

In our study, the incidence of PDPH using 27 G Quincke spinal needle was found to be $3.01 \%$. Time to mobilization has no statistical significance in producing PDPH. The awareness of these factors which increases the incidence of PDPH during spinal anaesthesia helps in preventing the pain of PDPH and its complications. As a century after August Bier first described PDPH, the optimal management of PDPH is a question that remains unanswered. It can also be a crucial step in preventing occurrence of such events by rational modification of the technique. Knowledge of such probable events in high risk patients will allow early recognition and appropriate therapeutic intervention, thus preventing occurrence of PDPH. Overall, the Whitacre $27 \mathrm{G}$ needle has better results with respect to PDPH.

\section{ACKNOWLEDGEMENT}

Authors would like to thank all the participants of study. Authors also acknowledge the immense help received from the scholars, whose articles are cited and included in references of this manuscript. The authors are also grateful to authors, editors and publishers of all those articles, journals and books from where the literature for this article has been reviewed and discussed.

\section{REFERENCES}

1. Phillip O Bridenbaugh, Nicholas M Greene, Sorin J Brull. Spinal neural blockade. In: Michael J Cousins, Phillip 0 Bridenbaugh, ed. Neural blockade in clinical anaesthesia and management of pain. Philadelphia: Lippincott Raven 1998;3rd edn:203-41.

2. Healy TEJ, Knight PR. Wylie and Churchill-Davidson's A Practice of Anaesthesia. London: Arnold; 2003; 7 th ed.

3. Hart JR, Whitacre RG. Pencil point needle in the prevention of post spinal headache. JAMA 1951;157: 657-8.

4. Lynch J, Kasper SM, Strick K, et al. The use of Quincke and Whitacre 27-gauge needles in orthopaedic patients: incidence of failed spinal anaesthesia of post-dural puncture headache. Anaest Analg 1994;79(1):124-8.

5. Despond O, Meuret P, Hemmings G. Post-dural puncture headache after spinal anaesthesia in young orthopaedic outpatients using 27 G needles. Can J Anaesth 1998;45(11):1106-9.

6. Lybecker $\mathrm{H}$, Moller JT, May $\mathrm{O}$, et al. Incidence and prediction of post-dural puncture headache. A prospective study of 1021 spinal anaesthesias. Anaesth Analg 1990;70(4):389-94.

7. Sudlow C, Warlow C. Posture and fluids for preventing post-dural puncture headache. Cochrane Database Syst Rev 2002;2:CD001790.

8. Sirakaran Tejavanija, Pasiri Sithinamsuwan, Nakorn Sithinamsuwan, et al. Comparison of prevalence of postdural puncture headache between six hour-supine recumbence and early ambulation after lumbar puncture in Thai patients: a randomized controlled study. J Med Assoc Thai 2006;89(6):814-20.

9. Bernard E Cappe. Prevention of post spinal headache with a 22-gauge pencil point needle and adequate hydration. Anaesth Analg 1960;39:463-5.

10. Cook PT, Davies MJ, Beavis RE. Bed rest and post lumbar puncture headache. The effectiveness of 24 hours' recumbency in reducing the incidence of post lumbar puncture headache. Anaesthesia 1989;44(5):389-91. 